\title{
Biografia como história social \\ o clã Ferreira Gomes e os mundos da escravização no Atlântico Sul*
}

\author{
Biography as social history \\ the Ferreira Gomes clan and the worlds \\ of slaving in the South Atlantic
}

\author{
ROQUINALDO FERREIRA** \\ Vasco da Gama Chair \\ Brown University \\ Providence (RI) \\ Estados Unidos
}

RESUMO Este artigo analisa as conexões econômicas e sociais en-
gendradas pelo tráfico de escravos entre Angola e Brasil, assim como o
abolicionismo português na primeira metade do século XIX. Neste sentido,
o artigo usa como ponto de partida a trajetória pessoal de José Ferreira
Gomes, um homem negro, nascido em Benguela, cuja mãe, Florinda José
Gaspar, era filha de um chefe africano da Catumbela e cujo pai, Francisco
Ferreira Gomes, foi um homem negro nascido no Brasil que tinha sido um
dos traficantes de escravos mais ativos em Benguela. Tendo como base a
biografia de Gomes Júnior, o artigo discute os laços sociais e culturais que
os traficantes de escravos angolanos mantinham com o Brasil e com as
populações africanas, a transição do tráfico de escravos para o comércio
lícito, e as mudanças na políticas portuguesas em relação ao tráfico de
escravos na década de 1840 . Para entender o recrudescimento do colonia-
lismo em Angola, o artigo examina acusações de que membros da família

Artigo recebido em: 27/10/2012. Autor convidado.

** Contato: roquinaldo_ferreira@brown.edu. 
Ferreira Gomes teriam participado de sedições raciais e anti-coloniais contra os portugueses.

Palavras-chave abolicionismo, história atlântica, escravidão

ABSTRACT This article deals with the social and economic ties that underpinned the slave trade from Angola to Brazil as well as the rise of Portuguese abolitionism in the first half of the nineteenth century. To that end, the article investigates the personal trajectory of José Ferreira Gomes, a black man born in Benguela whose mother, Florinda Josefa Gaspar, was the daughter of an African chief in Catumbela and the father, Francisco Ferreira Gomes, was a black man born in Brazil and one of the most active slave dealers in Benguela. By focusing on Gomes junior's career, the article sheds light on the social and cultural connections that Angolan slave dealers built with Brazil and African populations, the transition from the slave trade to legitimate commerce in Angola, and shifts in Portuguese policies towards shipments of slaves in Angola that took place in the 1840s. To further understand the rise of Portuguese colonialism in Angola, the article examines accusations that members of the Ferreira Gomes family led racial and anti-colonial sedition against the Portuguese.

Keywords abolitionism, atlantic history, slavery

\section{Introdução}

Em 1863, no Rio de Janeiro, Brasil, um brasileiro chamado José Francisco de Mesquita ajuizou uma ação contra seu avô, Francisco Ferreira Gomes, que então tinha 78 anos de idade. Na ação, Mesquita argumentava que sua avó, Florinda Josefa Gaspar, tinha morrido recentemente, mas que seu avô ainda não havia executado seu testamento. Gaspar era filha de um chefe africano da Catumbela, Benguela, que havia migrado para o Rio de Janeiro com Ferreira Gomes quase 30 anos antes. Mesquita afirmava que ainda não tinha recebido sua herança devido à demora na execução do testamento de sua avó. Mesquita havia sido criado por seus avós após o falecimento de sua mãe em 1843. No entanto, depois do ajuizamento da ação, o brasileiro Perdigão Malheiros, eminente advogado, teve que ser contratado para mediar os contatos entre ele e seu avô. ${ }^{1}$

O interesse de Mesquita pelo patrimônio de seus avós é fácil de entender. Nascido no Rio de Janeiro em 1785, o avô, Francisco Ferreira Gomes, era um homem negro, livre, que tinha sido, em 1800, exilado como

1 Arquivo Nacional do Rio de Janeiro (ANRJ). Inventário de Florinda Josefa Gaspar, 1863, n.1085, cx.4089, gal.A. 
criminoso em Benguela - o segundo maior porto de escravos de Angola. A despeito disso, conseguiu tornar-se um dos maiores negociantes de escravos da região. Entre 1809 e 1831, o velho Gomes enviou quase 7 mil cativos de Benguela para o Brasil, cerca de 7\% do número total de cativos embarcados naquela cidade na época. Ele chegou ao mais alto escalão da sociedade de Benguela, tornando-se chefe do tesouro real, juiz do juízo que administrava os bens de comerciantes falecidos (o Juízo dos Defuntos e Ausentes), e comandante da milícia local (o batalhão dos Henriques). Em 1834, ele retornou ao Rio de Janeiro, levando sua família africana com ele - incluindo a mãe de Mesquita. ${ }^{2}$

Este artigo se centra nessas duas gerações da família Ferreira Gomes e tem como objetivo entender as redes transatlânticas que davam sustentação ao comércio ilegal de escravos de Angola para o Brasil entre as décadas de 1830 e 1850. Durante essas décadas, aproximadamente 80 mil pessoas foram enviadas de Benguela às Américas, especialmente ao Rio de Janeiro. Embora ancorado nas últimas estimativas da Transatlantic Slave Trade Dataset, ${ }^{3}$ este artigo se afasta das análises estruturais sobre o comércio de escravos em Angola e está baseado amplamente em informações biográficas, de modo a explorar a forma como os traficantes de escravos se relacionavam com suas comunidades e com o amplo mundo atlântico à sua volta. Investiga ainda as medidas antiescravistas implementadas em Angola, situando-as no contexto mais amplo das políticas adotadas por Portugal com o intuito de extinguir o comércio de escravos em suas colônias africanas e fortalecer os seus laços coloniais com Angola. Ao se concentrar na carreira tardia de José Ferreira Gomes, o artigo aborda a tensão racial no contexto da abolição do tráfico de escravos em Angola.

\section{Conexões familiares e sociais através do Atlântico}

Para justificar o atraso em inventariar os ativos de sua família, o velho Gomes alegava que tinha sido incapaz de contatar seu filho mais velho, José Ferreira Gomes, que ainda vivia em Benguela e era o administrador local das propriedades e negócios da família. ${ }^{4}$ De acordo com o velho Gomes, uma carta rogatória teria que ser enviada a seu filho em Benguela, um processo que levaria pelo menos seis meses, o que refletia a diminuição das trocas marítimas realizadas entre Angola e o Brasil após o fim do tráfico de escravos em 1850. Em 1855, ao restabelecer o consulado brasileiro em Luanda, um diplomata brasileiro ofereceu a seguinte avaliação a respeito

2 FERREIRA, Roquinaldo. Cross-cultural exchange in the Atlantic World: Angola e Brazil during the Era of the Slave Trade. New York: Cambridge University Press, 2012, p.203-244.

3 http://www.slavevoyages.org/tast/index.faces. Acesso em: 27 out. 2012.

4 ANRJ. Carta de Francisco Ferreira Gomes, 05/081863, Inventário de Florinda Josefa Gaspar, n.1085, cx.4089, gal.A. 
das trocas comerciais com Angola: "Até agora, este comércio (entre o Brasil e Angola) tem sido muito limitado e quase apenas indireto". ${ }^{5}$

A afirmação do velho Gomes de que precisaria consultar seu filho, José Ferreira Gomes (Gomes Júnior), em Benguela mostra que, apesar de seu retorno ao Rio de Janeiro em 1834, ele permanecera ligado a Benguela. $\mathrm{Na}$ verdade, mesmo 20 anos depois de deixar Benguela, ele ainda era dono de propriedades e escravos na cidade, como demonstram documentos arquivados na década de 1850 por um juiz local. Um primeiro documento revela que "a mulher preta Dionísia, também conhecida como Juamutango, sempre foi escrava do justificante (Francisco Ferreira Gomes) desde que ele era um morador desta cidade (Benguela), tendo sido comprada do falecido Francisco Joaquim Coelho Santiago, do sertão de Galangue". ${ }^{6}$ Outro documento descrevia Gomes Júnior como proprietário de dois escravos que ele havia herdado - um homem chamado Quipaca e uma mulher chamada Quirombo. ${ }^{7}$

Depois de voltar ao Rio de Janeiro, o velho Gomes foi a Benguela apenas uma vez, em 1855. ${ }^{8}$ As propriedades e os negócios que a família possuía nessa localidade eram geridos por seu filho mais velho. Em 1834, por exemplo, Gomes Júnior aparecia como "o representante legal de seu pai, Francisco Ferreira Gomes", que vivia então no Rio de Janeiro. ${ }^{9}$ Em 1855, o velho Gomes declarava que, após ter "voltado ao Rio de Janeiro [em 1834], ele havia deixado sua casa comercial e suas propriedades aos cuidados de sua esposa, dada a ausência de seus filhos, José Ferreira Gomes e Joannes Ferreira Gomes, este último falecido. Em segundo lugar, depois da partida sua esposa para o Rio de Janeiro, seu filho José Ferreira Gomes tornou-se o gerente de sua casa de comércio e de suas propriedades". ${ }^{10}$

Desde tenra idade, Gomes Júnior tinha sido preparado para se tornar gerente dos negócios da família. Em muitos aspectos, sua formação cultural e social faziam dele a pessoa ideal para executar essa tarefa. Nascido em Benguela, em 1805, ele tinha ligações com o Brasil por intermédio de seu pai brasileiro e com Angola por intermédio de sua mãe africana, Florinda Josefa Gaspar. Seu primo materno era Johannes José Gaspar, chefe africano (soba) da Catumbela, região que desempenhava papel fundamental no fornecimento de alimentos para Benguela, e fora seu aliado quando as autoridades benguelenses se voltaram contra ele, na década de 1840, em razão de sua atuação política e de suas atividades no tráfico de escravos. Como seu pai, Gomes Júnior havia se casado com mulheres africanas, primeiro com Maria Nunes Romão e, em seguida, com Gertrudes Ferreira Gomes.

\footnotetext{
Arquivo do Itamaraty (Al). Ofício para o Futuro Cônsul do Brasil em Luanda, 1855, maço 252-4-6 (parte 1).

Tribunal da Comarca de Benguela (TCB). Autos Cíveis de Justificação, 17/10/1855, maço 7, n.348.

TCB. Requerimento de José Ferreira Gomes, 17/08/1857, maço 1, n.40.

Arquivo Histórico de Angola (AHA). Ofício do Secretário do Governo de Benguela, 11/12/1855, cód.468, fls.5v.-6.

9 AHA. Ofício da Junta Governativa de Benguela, 22/01/1835, cód.2310, fls.84v.-85v.

10 TCB. Auto de Sentença Cível, 1858, maço 2, n.85.
} 
Aos treze anos de idade, Gomes Júnior foi enviado ao Rio de Janeiro para ser educado. Ao dotar seu filho com uma educação brasileira, o velho Gomes seguia o exemplo de outros comerciantes de Benguela. Em 1829, um comerciante brasileiro chamado Justiniano José dos Reis "solicitou uma licença para enviar seu afilhado de dez anos, chamado Justiniano da Costa Covello, ao Rio de Janeiro para a sua educação". ${ }^{11}$ No mesmo ano, outro comerciante, Jácomo Felipe Torres, "solicitou licença para enviar ao Rio de Janeiro dois órfãos para serem educados por caridade". ${ }^{12}$ Embora refletisse a disponibilidade limitada de escolaridade nos moldes ocidentais em Benguela, essa prática forneceu a Gomes Júnior habilidades culturais e redes sociais que se revelariam particularmente úteis quando o movimento para acabar com o tráfico de escravos ganhou força na década de 1840.

Depois de regressar a Benguela, em 1821, Gomes Júnior se casou com sua primeira esposa, Maria Nunes Romão, uma órfã de 12 anos de idade que era herdeira de uma grande fortuna. ${ }^{13} \mathrm{O}$ casamento foi arranjado pelo velho Gomes - na época juiz do Juízo de Defuntos e Ausentes e tutor legal da órfã - que tinha servido com o pai da menina na milícia local, conhecida como batalhão dos Henriques. O pai de Romão era dono de uma grande casa comercial em Benguela, que lidava principalmente com o comércio de escravos entre Benguela e os sertões. Tinha também trabalhado como Inquiridor das Liberdades - oficial encarregado de investigar o estatuto legal dos africanos trazidos para Benguela como escravos e a legalidade de sua escravização. O velho Gomes foi acusado por seus críticos de usar sua posição como juiz para manipular a família da noiva para que permitisse o casamento, lucrando, assim, com a herança. ${ }^{14}$

O retorno de Gomes Júnior a Benguela marcou o início de sua carreira de negócios, que incluía uma variedade de tarefas como parceiro de seu pai nos negócios da família. Em 1825, por exemplo, ele foi descrito como "legalmente associado numa parceria comercial (com Francisco Ferreira Gomes) e é necessário que um dos parceiros viajem para o Rio (de Janeiro)" ${ }^{15}$ Investido nessas atribuições, ele viajaria ao Rio em 1826, 1827 e 1830, tornando-se, também, coproprietário de navios com seu pai. ${ }^{16}$ Ele

11 AHA. Despacho do Requerimento de Justiniano José dos Reis, 19/05/1829, cód.7182, fl.144V.

12 AHA. Despacho do Requerimento de Jácomo Felipe Torres, 23/09/1829, cód.7182, fl.169. Para outros casos de residentes em Benguela que mandaram seus filhos para serem educados no Brasil, ver FERREIRA, Roquinaldo. Atlantic microhistories: slaving, mobility, and personal ties in the Black Atlantic World (Angola and Brazil). In: NARO, Nancy; SANSI, Roger; TREECE, David. (org.). Cultures of the Lusophone Black Atlantic. New York: Palgrave Macmillan, 2007, p.99-128.

13 AHA. Portaria do Governador de Benguela, 16/11/1811, cód.519, fl.90v.

14 AHA. Ofício do Governo Provisorio de Benguela, 27/05/1822, cód.448, fls.22v.-23.

15 AHA. Ofício do Governador de Benguela, 27/10/1825, cód.449, fl.59; AHA. Requerimento de José Ferreira Gomes, 04/02/1826, cx.138, fl.163v.

16 AHA. Petição de José Ferreira Gomes, 04/02/1826, cx.138, fl.163v.; AHA. Requerimento de Francisco Ferreira Gomes e José Ferreira Gomes, 24/01/1827, cód.7182, fl.35; dados da homepage do Arquivo Nacional do Rio de Janeiro, Movimentação de Portugueses no Brasil, 1808-1842. Disponível em: www.arquivonacional.gov.br/cgi/cgilua.exe/ sys/start.htm?sid=166. Acessado em: 01 out. 2012; AHA, Petição de José Ferreira Gomes, 11/04/1839, cx.1602. 
também apoiava transações financeiras entre comerciantes de Benguela, emprestando-Ihes bens, muito provavelmente em nome de seu pai. ${ }^{17}$

Como seu pai, Gomes Júnior ocupava cargos na administração civil e militar de Benguela, desempenhando um papel ativo, embora controverso, na política da cidade. Em 1823, quando a cidade foi agitada por uma crise política após a independência do Brasil, ele jurou lealdade a Portugal juntamente com outros comerciantes proeminentes. ${ }^{18} \mathrm{Em} \mathrm{1830}$, foi descrito como um "muito diligente e altamente considerado" oficial do batalhão dos Henriques. ${ }^{19} \mathrm{Em}$ 1835, no entanto, as autoridades acusaram-no e a seu irmão de conspirar contra a administração colonial e de usar seus escravos para aterrorizar os residentes de Benguela. ${ }^{20}$

Seria a carreira de Gomes Júnior, em particular suas conexões com o Brasil e suas constantes viagens ao exterior, representativa do modus operandi da comunidade comercial mais ampla de Benguela? Como ele, outros comerciantes de Benguela tinham profundas ligações com o Brasil por meio de negócios ou de laços familiares e viajavam ao Brasil regularmente. O comerciante português José Joaquim Teixeira é um caso típico. Homem branco nascido no Porto, Teixeira havia apoiado o projeto de criação de uma companhia agrícola e fora nomeado comandante de uma das fortalezas de Benguela. ${ }^{21}$ Mais importante ainda, ele tinha fortes ligações com o Rio de Janeiro, cidade à qual enviou sua filha para ser educada e onde procurou atendimento médico na década de 1840.22

Outros comerciantes haviam nascido no Brasil ou tinham laços familiares que se estendiam através do Atlântico. Nascido no Brasil, Manoel Vidal Cesar escreveu em 1858: "Meus (dois) irmãos vivem nesta cidade (Benguela), um (irmão) no Rio de Janeiro e uma irmã no Rio de Janeiro". ${ }^{23}$ José Gaspar Lobo havia nascido no Rio de Janeiro, mas comerciava em Benguela em nome de seu irmão João Gaspar Lobo, um comerciante estabelecido no Rio de Janeiro que havia enviado a Benguela carregamentos de bens em oito navios diferentes entre 1850 e $1853 .{ }^{24} \mathrm{O}$ caso de Veríssimo Lopes de Moura também é ilustrativo. Nascido no Brasil, Moura se tornou juiz em Benguela, declarando, em 1858: "Antonio Leite Ribeiro, mora(dor) no Rio

17 AHA. Requerimento de João Pedro de Andrade, 20/11/1827, cód.7182, fl.73v.

18 Arquivo Histórico Ultramarino (AHU). Angola, Conferência da Câmara de Benguela, 03/01/1823, cx.142, doc.44.

19 AHU. Angola, Informação Semestral da Companhia de Henriques de Benguela, 01/07/1830, cx.167, doc.45.

20 AHU. Segunda seção de Angola, pasta 2, Ofício de Justiniano José dos Reis, 18/12/1836; AHA. Ofício da Junta Governativa de Benguela, 17/02/1835, cód.2310, fls.85v.-86; AHA. Carta para o Juiz do Crime Interino, 11/08/1835, cód.163, fls.10-10v.; AHA. Ofício da Junta Governativa de Benguela, 17/02/1835, cód.2310, fls.85v.-86.

21 AHA. Ofício do Secretário Geral da Província de Angola, 23/11/1846, cód.3440, fls.183-183v.; AHA. Ofício do Governador de Benguela, 04/10/1848, cód.462, fls.134-134v.

22 AHA. Cód.521, fl.48; AHA. Cód.522, fl.70v.; AHA. Ofício do Governador de Benguela, 28/08/1847, cód.462, fl.9v.

23 TCB. Autos de Inventário de Manuel Vidal Cesar, 1858, n.215.

24 TCB. Testemunho de Verissimo Lopes Moura, 1855, maço 7, n.313. Gaspar tinha vários contatos em Benguela, entre os quais conhecidos traficantes de escravos, como Manoel Antonio Teixeira Barboza e José Luis da Silva Vianna. No entanto, o contato principal dele era seu irmão José Gaspar Lobo. Ver: TCB. Translado de Autos Cíveis de Libelo Comercial, 1855, n.38. 
de Janeiro, contador de um comerciante que mora na cidade, cujo nome é Francisco José Pacheco, (que) me deve oito contos, novecentos e um mil e setenta réis de uma dívida". 25

Essas conexões transatlânticas eram importantes em pelo menos dois níveis. Além de prover os comerciantes com a literacia cultural necessária para que pudessem se dedicar ao comércio em ambos os lados do Atlântico, elas tornaram mais difícil acabar com o tráfico transatlântico de escravos em Angola. Isso é demonstrado pela trajetória de Manoel Joaquim Teixeira. Descrito como um dos mercadores mais ricos de Benguela (juntamente com José Ferreira Gomes), Teixeira recebeu 100 escravos dos sertões em $1839 .{ }^{26} \mathrm{Em} 1844$, foi nomeado governador interino de Benguela, mas, apenas três dias após sua nomeação, pediu uma licença para viajar para o Rio de Janeiro - sinalizando suas conexões através do Atlântico. ${ }^{27}$

Teixeira voltou a Benguela, mas viajou novamente ao Rio em 1846 muito provavelmente para fugir da crescente repressão local ao tráfico de escravos. No Rio, manteve laços estreitos com Benguela, até mesmo contribuindo com dinheiro para a manutenção do hospital da cidade. ${ }^{28}$ Mais importante ainda, sua estada no Rio não o impediu de investir no comércio de escravos em Benguela por meio de uma rede de parceiros que incluía um brasileiro chamado Bento Pacheco dos Santos..$^{29}$ Depois de ser forçado a sair do Brasil devido à sua participação no tráfico de escravos, Teixeira voltou a Benguela, onde organizou o envio de escravos para Cuba em 1850. Em 1853, autoridades afirmaram que Teixeira era "um velho comerciante em Benguela, mas havia se mudado para Rio de Janeiro em 1846, onde acumulou fortuna considerável em especulações ilícitas no tráfico de escravos, até ser forçado a deixar o Brasil pelo governo imperial (brasileiro)" ${ }^{30}$

\section{O movimento contra o tráfico de escravos}

A partir do início da década de 1830, a expansão das medidas contra o tráfico de escravos no Atlântico Sul gradualmente afetou o comércio de escravos em Angola. Em 1831, as importações de escravos no Brasil foram proibidas, provocando uma crise financeira em Luanda, principal porto do comércio de escravos de Angola, e levando à disseminação de pontos de

25 TCB. Inventário de Veríssimo Lopes de Moura, 1858, não numerado.

26 AHA. Ordem do Governador de Benguela, 21/11/1839, cód.522, fls.34-35; AHA. Requerimento de Manoel Joaquim Teixeira Barboza, 29/05/1839, cx.1602.

27 AHA. Ofício do Governador de Benguela, 26/03/1844, cód.455, fl.51.

28 AHA. Ofício do Secretário do Governo de Benguela, 24/07/1846, cód.461.

29 AHA. Ofício do Governador de Benguela, 05/07/1848, cód.722, fls.253-254. Para outras evidências dos negócios de Barboza em Benguela no período em que ele esteve no Rio, bem como dos laços entre Barboza e Bento Pacheco dos Santos, ver: AHA. Ofício do Governador de Benguela, 14/08/1848, cód.722, fl.261; AHA. Ofício do Secretário de Governo de Benguela, 03/12/1853, cód.459, fls.20-22; Arquivo Nacional da Torre do Tombo (ANTT). MNE, Manifesto de Carga do Bergatim Americano Susan, 01/02/1849, cx.374.

30 AHA. Ofício do Governador de Benguela, 05/12/1853, cód.459, fls.22v-25v. 
embarque em regiões fora da cidade, como Ambriz e outros locais. Essa evolução constituiu a base para a continuidade do tráfico de escravos em Ambriz e em outras regiões próximas ao Rio Congo até a década de 1850, apesar dos embarques de escravos em Luanda terem findado em meados da década de 1840. ${ }^{31}$ Em Benguela, os embarques de escravos diminuíram ainda mais após 1831. Enquanto 25.097 cativos foram enviados a partir dessa cidade entre 1826 e 1830, o seu número diminuiu para 2.684 entre 1831 e $1835 .{ }^{32}$

A motivação portuguesa para acabar com o comércio de escravos originou-se de dois fatores. Em primeiro lugar, depois que o Brasil se tornou independente, em 1822, Portugal procurou criar uma nova economia em Angola, com o intuito de fortalecer os laços com sua colônia africana e reduzir as conexões entre Angola e o Brasil. ${ }^{33} \mathrm{Em} 1830$, autoridades afirmaram que as "relações comerciais com a pátria-mãe estão muito reduzidas" ${ }^{34}$ Entre 1830 e 1832, dos navios que entraram no porto da cidade, mais de 90 eram provenientes do Brasil, enquanto apenas 11 provinham de Portugal. ${ }^{35} \mathrm{Em}$ 1836, as autoridades afirmaram que "hoje este reino tem relações comerciais mais ativas com o Brasil, um país estrangeiro" que com Portugal, e recebe do Brasil "todos os bens produzidos na Europa". ${ }^{36} \mathrm{~A}$ partir de meados da década de 1840, no entanto, essa situação mudou gradualmente. Em fevereiro de 1850, apenas oito dos quarenta e cinco navios entrados em Luanda não eram portugueses. ${ }^{37}$ Dois anos mais tarde, um viajante português afirmou que mais da metade dos 80 navios que haviam entrado Luanda tinham partido de Lisboa. ${ }^{38}$

Em segundo lugar, os portugueses temiam que os britânicos pudessem usar a campanha para acabar com o comércio de escravos para fazer reivindicações sobre territórios em Angola que os portugueses consideravam seus. Os britânicos tinham começado a percorrer as águas angolanas

31 FERREIRA, Roquinaldo. The suppression of the slave trade and slave departures from Angola, 1830s-1860s. In: ELTIS, David; RICHARDSON, David. Extending the frontiers: essays on the New Transatlantic Slave Trade Database. New Haven: Yale University Press, 2008, p.313-334.

32 ELTIS, David; BEHRENDT, Stephen; David, RICHARDSON, David; KLEIN, Herbert. The Transatlantic Slave Trade: a database on CD-Rom. Cambridge, 1999. A base de dados revisada está disponível em: <www.slavevoyages. org >. Acesso em: 27 out. 2013.

33 FERREIRA, Roquinaldo. Agricultural enterprise and unfree labor in Nineteenth-Century Angola. In: STRICKROD, Silke; LAW, Robin. (org.). Commercial agriculture as an alternative to the Transatlantic Slave Trade in Africa (não publicado). Ver também ALEXANDRE, Valentim, The Portuguese Empire, 1825-1890: ideology and economies. In: PÉTRÉ-GRENOUILLEAU, Olivier. (ed.). From slave trade to empire: Europe and the colonization of Black Africa, 1780s-1880. New York: Routledge, 2004, p.110-132; MARQUES, João Pedro, The sounds of silence: NineteenthCentury Portugal and the abolition of the slave trade. New York: Berghahn, 2006; PAQUETTE, Gabriel. After Brazil: portuguese debates on Empire, c. 1820-1850. Journal of Colonialism and Colonial History, v.11, n.2, 2010.

34 AHA. Ofício do Governador de Angola, 11/10/1830, cód.12, fls.39-41.

35 LIMA, José Joaquim Lopes de. Ensaios sobre a Statistica das Possessões Portuguezas na Africa Occidental e Oriental; na Asia Occidental; na China e na Oceania. Lisboa: Imprensa Nacional, 1846, p.74.

36 AHA. Ofício do Governador de Angola, 08/04/1836, cód.13, fls.1-3; Biblioteca Nacional de Lisboa (BNL). Carta de Manoel da Cruz, 20/10/1837, cód.600.

37 AHU. Rendimentos da Alfândega de Luanda em 1850, segunda seção de Angola, pasta 16.

38 CALDEIRA, Carlos José. Apontamentos d'uma viagem de Lisboa à China. Lisboa: Typographia de Castro \& Irmão, 1853, p.214-215. 
em busca de navios negreiros mesmo antes da assinatura de um Tratado Antitráfico com Portugal em 1844. Em 1836, por exemplo, o governador de Angola, Domingos de Saldanha Oliveira Daun, ordenou que a artilharia de Luanda abrisse fogo contra um navio de guerra britânico. ${ }^{39}$ Dois anos mais tarde, o recém-nomeado governador de Angola, Antônio Manoel de Noronha, destacou que "a continuação do comércio é agora imprópria sem expor essas províncias aos insultos dos cruzadores britânicos e dando-lhes o pretexto para entrar em negociação direta com os vizinhos (africanos) na costa (...) trazendo a dúvida e a precariedade à soberania portuguesa nessas regiões". ${ }^{40}$

Embora os portugueses estivessem particularmente preocupados com as ambições britânicas em Ambriz e Cabinda, regiões ao norte de Luanda nas quais o controle dos portugueses sempre havia sido fugidio, eles também se preocupavam com a presença de cruzadores britânicos em Benguela. Em 1841, por exemplo, o governador de Angola, Manoel Eleutério Malheiro, ordenou ao governo de Benguela que investigasse informações de que os britânicos haviam estabelecido um alojamento na cidade de Lobito, perto de Benguela.$^{41}$ As preocupações portuguesas aumentaram em 1842, quando as forças britânicas bloquearam o porto de Benguela e apreenderam um navio brasileiro (Eliza), que tinha 392 escravos a bordo. ${ }^{42}$ Mais tarde, a administração desse porto informou que um navio britânico havia tentado "registrar" navios portugueses e isso feriria a soberania portuguesa. ${ }^{43}$

Apesar de um decreto real de 1836, que tornava ilegal a expedição de escravos das colônias portuguesas na África, o comércio de escravos estava se intensificando em Benguela entre 1836 e 1840, quando quase 30 mil pessoas foram levadas para as Américas. Ainda em 1836, o governador de Angola, Domingos Saldanha de Oliveira Daun, afirmava que, embora os embarques de escravos em Luanda tivessem cessado, o mesmo não havia acontecido em Benguela. ${ }^{44}$ Não surpreendentemente, todos os nove navios negreiros apreendidos ao largo da costa do Rio de Janeiro entre maio e julho de 1837 haviam partido dessa cidade. ${ }^{45}$ George Tams, um viajante alemão que visitou Angola no início da década de1840, escreveu que 20 mil cativos haviam sido enviados de Benguela em $1838 .{ }^{46}$ De acordo com as

39 AHU. Ofício do Governador de Angola, 08/04/1836, segunda seção de Angola, pasta 2.

40 AHU. Relatório do Governador de Angola, 06/08/1838, segunda seção de Angola, pasta 3.

41 AHA. Ofício do Governador de Angola, 12/06/1841, cód.15, fl.55v. O governo de Angola acabaria por enviar um navio de guerra a Benguela e Mossamedes para investigar tais rumores. Ver: AHA. Ofício do Conselho de Governo de Angola, 04/09/1842, cód.15, fl.120v.

42 AHA. Portaria da Secretaria de Governo da Marinha e Ultramar, 20/06/1843, cód.261, fls.12-12v.; AHA. Edital do Governador Interino de Benguela, 25/05/1843, cód.522, fls.172v.-174; AHA. Portaria da Secretaria de Governo da Marinha e Ultramar, 06/09/1843, cód. 261, fls. 38v.-39.

43 AHA. Ofício do Secretário de Governo de Benguela, 18/10/1843, cód.454, fls.76-76v.

44 AHA. Ofício do Governador de Angola, 11/06/1836, cód.13, fls.28v.-29v.

45 AHU. Ofício de Sá da Bandeira para o Governador de Angola, 1837, papéis de Sá da Bandeira, maço 824.

46 TAMS, George. Visita às Possessões Portuguesas na Costa Ocidental da África. Porto: Typographia da Revista, 1850, p. 110. 
fontes britânicas, no período de apenas um mês, pelo menos cinco navios haviam levado escravos da cidade em 1841.47

Essa situação decorria da cumplicidade oficial com os embarques de cativos, apesar da existência de leis anti-tráfico. Em 1839, por exemplo, um comerciante de escravos dizia, no Rio, que cativos eram embarcados "durante o dia, em Benguela, na frente de autoridades do país". ${ }^{48} \mathrm{Em} 1841$, um governador de Benguela foi demitido após ser acusado pelos ingleses de viajar ao Brasil para negociar escravos. ${ }^{49}$ Benguela foi, então, sucessivamente governada por dois governadores interinos - ambos comerciantes locais que acabaram sendo acusados de envolvimento no tráfico negreiro. ${ }^{50}$ Com medo de que os britânicos invadissem a cidade, a administração de Luanda despachou José Fortunato da Costa, um militar local, para ser o novo governador de Benguela. ${ }^{51}$ No entanto, após apenas dois meses de exercício, o governador foi demitido sob a acusação de conivência com o tráfico de escravos. ${ }^{52}$

O aumento dos embarques de escravos em Benguela se devia também à introdução de novas técnicas na condução do comércio negreiro, que permitiam aos traficantes transportar cativos através do Atlântico, evitando os cruzadores navais britânicos. Para escapar da captura, os navios eram registrados como se estivessem velejando do Rio de Janeiro a Montevidéu, com escalas em diversos portos africanos. ${ }^{53}$ Entre outubro de $1835 \mathrm{e}$ agosto de 1838, 46 navios negreiros declararam destinações enganosas ao partir de Benguela - geralmente anunciando Montevidéu e Moçambique como destino final. ${ }^{54}$ Antes de atravessar o Atlântico em direção ao Brasil, a maioria das embarcações, se não todas elas, teriam ido a lugares próximos a Benguela, como Hanha, Egito, Catumbela e Lobito. ${ }^{55}$ Ao fazer isso, elas evitavam a repressão em Benguela. Como um governador de Benguela afirmava em 1850, "esses (carregamentos) ocorreram com maior frequência nos portos ao norte do distrito, como Egito, Quicombo, Novo Redondo e Benguela Velha". ${ }^{56}$

47 AHA. Portaria da Secretaria de Estado da Marinha do Ultramar, 26/05/1841, cód.260, fls.53v.-54v.

48 AHI. Processo do Navio Feliz (1838-1839), Coleções Especiais, lata 15, maço 4, pasta 1.

49 As autoridades portuguesas argumentaram que o governador havia viajado ao Brasil por motivos de saúde, não para traficar escravos. Ver: AHA. Ofício do Governador de Angola, 17/01/1841, cód.15, fls.31v.-32v. No entanto, eles logo despediram-no. Ver: AHA. Decreto Régio, 02/03/1841, cód.260, fls.17v.-18.

50 AHA. Ofício do Governador de Angola, 04/04/1841, cód.15, fls.45v.-46v.; AHA. Ofício do Governador de Angola, 12/06/1841, cód. 15, fls.55-55v.

51 AHA. Ofício do Governador de Angola, 20/07/1841, cód.15, fls.60-60v.

52 AHA. Ofício do Comandante da Corveta Oito de Julho, 21/10/1841, cód.452, fls.74-74v.

53 AHA. Passaporte da Sumaca Rio Tâmega, 31/10/1835, cód.521, fls.12v.-13; AHI. Processo do Paquete do Sul, 1833-1834, Coleções Especiais, lata 25, maço 4, pasta 1. Ver: ELTIS, David. Economic growth and the ending of the Transatlantic slave trade. New York: Oxford University Press, 1987; BORUCKI, Alex. The "African Colonists" of Montevideo: new light on the slave trade to Rio de Janeiro and Rio de La Plata (1830-1842). Slavery and Abolition, v.30, n.3, p.427-444, 2009

54 AHA. Cód.521.

55 AHA. Registro de Requerimentos, 1843-1846, cx. 151. Ver também BOUET-WILLIAUMEZ, Edouard. Commerce et traite des noires aux côtes occidentales d'Afrique. Paris: Imprimerie Nationale, 1848, p.177-178.

56 AHU. Ofício do Governador de Benguela, 02/04/1850, segunda seção de Angola, pasta 16A. 
Significativamente, a incapacidade dos portugueses de erradicar os embarques de escravos resultava também da influência de indivíduos que, como Gomes Júnior, usavam seu poder para minar as medidas anti-tráfico. Justiniano José dos Reis, um traficante de escravos nascido no Brasil que havia sido coproprietário de um navio negreiro com o velho Gomes, é um exemplo. Como governador interino de Benguela, Reis fora incumbido de aplicar o decreto português que tornava ilegal o comércio de escravos em 1836. Ao mesmo tempo em que ordenava a revista dos navios negreiros que chegavam ao porto da cidade, ele também possuía o Brigue Nova Sorte, que desembarcou 444 escravos no Rio de Janeiro em 1836. ${ }^{57}$ Anos mais tarde, quando as autoridades apreenderam um pequeno barco envolvido no tráfico de escravos, José Luis da Silva Viana, homem que se tornaria mais tarde governador de Benguela, defendeu, com sucesso, a soltura do barco..$^{58}$

No início da década de 1840, no entanto, medidas anti-tráfico ganharam impulso. Essas medidas não acabaram com o tráfico de escravos e, na verdade, cerca de 30 mil cativos africanos foram enviados de Benguela para as Américas entre 1841 e 1845. Elas, todavia, mudaram o ambiente geral em que os traficantes de escravos operavam. Elas envolveram, por exemplo, a repressão à leniência oficial contra o tráfico, levando à prisão vários indivíduos cúmplices dos traficantes de escravos, incluindo o secretário do governador de Benguela. ${ }^{59}$ Elas incluíram restrições à entrada de escravos em Benguela, por meio da criação de uma taxa sobre cada cativo levado para a cidade. ${ }^{60}$ Da mesma forma, elas levaram à regulamentação mais rigorosa do comércio de pólvora, limitando o acesso a uma das principais matérias-primas utilizadas no comércio de escravos nos sertões. ${ }^{61}$

Como Gomes Júnior reagiu a esse novo ambiente? Ele começou a comerciar urzela, um produto usado para tingir tecidos e em alta demanda na Europa, estabelecendo fazendas conhecidas como feitorias, dedicadas à extração e venda de urzela ao longo da costa de Benguela. Em 1845, o governador de Benguela declarou que (José) "Ferreira Gomes havia se estabelecido nesta cidade com uma casa comercial e tinha feitorias no litoral norte da cidade". ${ }^{62}$ Ao investir no comércio de urzela, Gomes Júnior seguia o exemplo de vários outros comerciantes de Angola. Em 1835, por exemplo,

57 Reis ordenou a investigação dos dois navios negreiros porque eles eram estrangeiros e representavam uma ameaça ao interesse comercial dos comerciantes de Benguela. Ver: AHA.Ordem do Governador de Benguela, 12/06/1836, cód.521, fl.34. Para a brigue Nova Sorte, ver AHA. cód.521, fls.24-24v.

58 AHA. Ofício do Governador Interino de Benguela, 09/02/1847, cód.7183. Para informação em Vianna, ver também TAMS, George. Visita às Possessões Portuguesas na Costa Ocidental da África, p.145.

59 AHA. Portaria do Governador de Benguela, 07/07/1840, cód.522, fls.63-63v.

60 Os proprietários de escravos que deixassem de acatar essa provisão perderiam seus escravos. Ver: AHA. Bando sobre os Escravos Novos, 07/01/1841, cód.522, fls.83v.-84; AHA. Bando sobre os Escravos entrados em Benguela, 16/12/1841, cód.522, fls.128v.-129.

61 AHA. Bando sobre a Pólvora em Benguela, 11/10/1841, cód.522, fl.125 v.-126; AHA, Requerimento de Antonio Xavier Vandunem, 04/05/1842, cód.1602.

62 AHA. Ofício do Governador de Benguela, 05/06/1845, cód.459, fls.1v.-2. 
a famosa comerciante de escravos Ana Joaquina dos Santos Silva era proprietária de uma dessas feitorias. ${ }^{63}$ Quatro anos mais tarde, os pedidos de Jácomo Felipe Torres, um comerciante em Benguela, revelam que ele era o proprietário de vários desses estabelecimentos ${ }^{64}$ Outro proprietário de uma feitoria de urzela era o brasileiro Raimundo Lapinberg, um comerciante de nível médio, levado por suas viagens a Salem, nos Estados Unidos. ${ }^{65}$ Outro brasileiro que investiu no comércio de urzela foi o já mencionado Veríssimo Lopes de Moura, que escreveu em seu testamento: "Declaro que possuo uma feitoria para extrair urzela em Lucira". ${ }^{66}$

Para comercializar urzela, esses comerciantes tinham de furar o monopólio real que obrigava a venda de toda a urzela coletada em Angola para os portugueses. Essa política monopolista beneficiava os comerciantes metropolitanos, que ofereciam preços baixos pelo produto, e foi contestada duas vezes por meio de petições enviadas a Lisboa por comerciantes angolanos. ${ }^{67} \mathrm{Na}$ ausência de uma mudança na política monopolista portuguesa, o contrabando de urzela tornou-se endêmico. Em 1840, por exemplo, três navios (dois se dirigiam ao Rio e o outro, a Londres) deixaram Benguela com o produto, apesar da proibição real. ${ }^{68}$ Mais tarde, as autoridades afirmaram que "as feitorias no litoral, tanto ao sul quanto ao norte do distrito (de Benguela), têm causado grandes danos ao tesouro nacional porque são pontos onde ocorre o contrabando (de urzela)". ${ }^{69}$

Para aumentar o volume da arrecadação, o governo de Luanda permitiu que os comerciantes angolanos vendessem livremente 30 mil arrobas de urzela - quase metade das exportações oficiais do produto na época. ${ }^{70}$ Significativamente, essa mudança na política havia se originado em Luanda, não em Lisboa, levando ao aumento das feitorias de urzela ao longo da costa angolana. Segundo as autoridades, "em todos os lugares ao longo da costa, até mesmo onde não havia nenhuma autoridade portuguesa, havia feitorias que pertenciam aos comerciantes desta cidade (Luanda) e de Benguela, todas voltadas para o comércio lícito e onde são coletados urzela, goma copal e outros bens deste país". ${ }^{71}$

63 AHA. Ofício da Junta Governativa de Angola, 05/12/1835, cód.8-1-59, fls.103-103v.

64 AHA. Registro de Requerimentos, 16/07/1839, cx.1602, fl.51v.; AHA. Requerimento de Jácomo Felipe Torres, 03/09/1839, cx.1602; AHA. Portaria do Ministro da Marinha e Ultramar, 12/12/1839, cód.259, fls.102v.-103; AHA. Despacho do Requerimento de Jácomo Felipe Torres, 31/06/1845, cx.151. AHA. Cx.1602. Jácomo Felipe Torres era o proprietário do navio Onze de Março. Ver AHA. Requerimento de Jacomo Felipe Torres, 16/07/1839, cx.1602, fl.51V.

65 AHA. Passaporte, 30/08/1844, cód.522, fl.203; AHA. Ofício do Secretário de Governo de Angola, 28/10/1851, cód.326, fls.197-197v.

66 TCB. Inventário de Veríssimo Lopes de Moura, 1858, não numerado.

67 AHU. Representação de José Ribeiro dos Santos, 11/1841, segunda seção de Angola, pasta 4B; AHA. Ofício do Governador de Angola, 23/12/1844, cód.16, fls.77-77v.

68 AHA. Portaria do Ministro da Marinha e Ultramar, 28/03/1840, cód.259, fls.135v.-136v.

69 AHA. Ofício do Governador Interino de Benguela, 07/08/1844, cód.455, fl.64.

70 Arquivo Histórico Nacional de Angola (AHNA). Ata da Sessão do Conselho de Governo, 25/10/1848, cód.2856, fls.110-112; AHU. Decreto do Governo de Angola, 02/11/1848, segunda seção de Angola, pasta 14.

71 AHU. Ofício do Governador de Angola, 09/12/1850, segunda seção de Angola, pasta 17A. 
As feitorias de urzela dependiam amplamente de força de trabalho escrava. Em 1850, cerca de 200 escravos trabalhavam em feitorias no sul de Benguela. ${ }^{72} \mathrm{Um}$ único residente de Benguela tinha 109 africanos trabaIhando como escravos em uma de suas feitorias. ${ }^{73}$ Essa dependência do trabalho escravo levou ao aumento dos negócios escravistas em Benguela. O brasileiro Joaquim Raimundo Lapinberg, por exemplo, comprou, em certa ocasião, 70 escravos para trabalharem em suas feitorias. ${ }^{74}$ É igualmente relevante que, apesar de dedicados ao comércio legal de urzela, esses estabelecimentos também eram utilizados como pontos de carregamento de escravos, uma vez que estavam espalhados ao longo da costa em territórios sobre os quais as autoridades tinham pouco controle. ${ }^{75}$ Escravos levados para essas feitorias para trabalhar na coleta de urzela acabavam sendo expedidos além-mar. Como resposta a essa situação, os proprietários de feitorias foram obrigados a registar seus cativos e a pagar multas se os escravos fossem enviados através do Atlântico. ${ }^{76} \mathrm{Em} 1860$, no entanto, as feitorias de urzela ainda estavam sendo usadas como base para a expedição de escravos ao exterior. ${ }^{77}$

\section{Políticas raciais e decadência financeira}

Apesar das restrições impostas às feitorias de urzela não terem coibido o uso desses estabelecimentos no comércio de escravos, elas afetaram os negócios de Gomes Junior. Em 1840, por exemplo, quando ele pediu permissão para viajar a uma de suas feitorias no Egito para finalizar a venda de uma carga de urzela a um navio americano, as autoridades o advertiram de que aquela seria a última vez em que ele seria autorizado a viajar para lá. ${ }^{78} \mathrm{Em} \mathrm{1842,} \mathrm{ao} \mathrm{renovar} \mathrm{uma} \mathrm{licença} \mathrm{para} \mathrm{viajar} \mathrm{a} \mathrm{uma} \mathrm{feitoria} \mathrm{na}$ Equimina, Gomes Júnior foi informado que ele seria responsabilizado se o estabelecimento fosse usado no comércio de escravos. ${ }^{79}$ Dois anos mais tarde, buscando antecipar as acusações de envolvimento com o tráfico de escravos, ele pediu para ser acompanhado por um funcionário da alfândega de Benguela, ao solicitar uma licença para visitar sua feitoria no Egito. ${ }^{80}$

\footnotetext{
72 AHA. Ofício do Governador de Benguela, 27/03/1850, cód.459, fls.6-7v.

73 AHA. Ofício do Secretário Geral do Governo de Angola, 24/04/1850, cód.511, fls.218-218v.

74 AHA. Ofício do Governador de Benguela, 15/04/1852, cód.465, fls.54v.-55.

75 WISSENBACH, Maria Cristina. As feitorias de urzela e o tráfico de escravos: George Tams, José Ribeiro dos Santos e os negócios da África Centro-Ocidental na década de 1840. Revista Afro-Ásia, v.43, p.43-90, 2011.

76 AHA. Circular aos Negociantes de Benguela, 19/03/1850, cód.461, fls.22v.-23v.

77 AHU. Ofício do Governador de Mossamedes, 19/11/1860, segunda seção de Angola, pasta 26.1

78 AHA. Petição de José Ferreira Gomes, 10/06/1840, cx.1602; AHA. Requerimento de José Ferreira Gomes, 17/07/1840, cx.1602.

79 AHA. Requerimento de José Ferreira Gomes, 13/08/1842, cx.1602. A mesma política foi aplicada a Alexandre José da Cruz, que pediu uma licença para viajar de Benguela para o Egito no mesmo ano. Ver: AHA. Requerimento de Alexandre José da Cruz, 28/08/1842, cx.1602.

80 AHA. Ofício do Secretário de Governo de Benguela, 07/11/1844, cód.456, fls.112v.
} 
No entanto, esses constrangimentos são pálidos em comparação aos problemas que Gomes Júnior enfrentou em 1845, quando foi preso sob a acusação de conspirar para uma sedição racial contra o governo colonial e a população branca de Benguela. De acordo com o viajante alemão George Tams, havia 300 brancos em Benguela no início de $1840 .{ }^{81}$ A maioria desses indivíduos viveria em regiões próximas à cidade, como mostrado mais tarde por um censo, que listou 78 brancos em Benguela propriamente dita em 1860.82 Gomes Júnior e seu irmão Joannes Ferreira Gomes teriam instigado "o povo de Catumbela a matar um regente a e ir a Benguela para matar os brancos, que eles diziam estarem se apropriando de suas terras". ${ }^{83}$ Como afirmado pelo governador de Angola, Pedro Alexandrino da Cunha, esses "negros Ferreira Gomes são inimigos pertinazes dos brancos e têm constantemente conspirado contra eles". ${ }^{84}$

Essas acusações puseram em evidência a dura tensão racial que havia emergido não só na sociedade de Benguela, mas também em Luanda como resultado da luta para acabar com o tráfico de escravos e para reforçar o controle colonial português sobre Angola. Conforme apontado por Jill Dias, algumas dessas tensões eram imaginárias, decorrentes da ansiedade portuguesa com o fato de que o número de negros e mestiços era bem maior que o de portugueses brancos..$^{85}$ No entanto, elas também refletiam 0 crescente número de europeus que ocupavam posições que anteriormente haviam sido ocupadas por moradores. Em Luanda, por exemplo, essas tensões transbordaram após a prisão de um homem mestiço (Nicolau Castelobranco), acusado de encorajar a insubordinação dos trabalhadores negros e de tramar o assassinato de brancos europeus. ${ }^{86}$ Em Benguela, elas eram "alimentadas por mulatos inquietos, que chamam publicamente os portugueses europeus de Galegos, dizendo que a África é só para eles (os indivíduos mestiços)". ${ }^{87}$

Para escapar das forças coloniais, Gomes Júnior procurou refúgio no território de seu primo materno, soba Johannes José Gaspar. ${ }^{88}$ Entretanto, Joannes Ferreira Gomes morreu (ou suicidou-se) em um navio de guerra português, e as autoridades levaram Gomes Júnior para Luanda, pois temiam que ele escapasse se fosse levado para Benguela. ${ }^{89}$ Ele foi mantido por três meses sob custódia, condenado ao degredo no posto colonial

81 TAMS, George. Visita às possessões portuguesas na Costa Ocidental da África, p.111.

82 AHNA. Mapa Estatístico do Distrito de Benguela, 1860, Benguela, cx.5568.

83 AHU. Notas dos crimes cometidos por José Ferreira Gomes, segunda seção de Angola, pasta 10A.

84 AHU. Ofício do Governador de Angola, 14/11/1846, pasta 10A.

85 DIAS, Jill. Angola. In: ALEXANDRE, Valentim; DIAS, Jill (eds.). Nova História da Expansão Portuguesa: o Império Africano. v.X, Lisboa, Editorial Estampa, 1998, p.377.

86 AHU. Ofício do Governador de Angola, 12/04/1839, segunda seção de Angola, pasta 4.

87 AHU. Ofício do Subdelegado Antonio Tavares da Silva Castelo Branco, 26/12/1849, segunda seção de Angola, pasta 16A.

88 AHA. Ofício do Governador de Benguela, 11/12/1845, cód.455, fls.132-132v.

89 AHA. Ofício do Comandante da Escuna Ninfa, 26/12/1845, cód.7183, fl.84. 
ao leste de Pungo Andongo, mas acabou sendo autorizado a regressar a Benguela. ${ }^{90}$ Nos termos de sua libertação, no entanto, ele se comprometeu a fazer visitas regulares à Luanda. Em 1849, um passaporte emitido pelo governo angolano descreveu-o como um negro de 44 anos, viajando de Benguela a Luanda, com seis servos pessoais, a mulher negra livre Joana Fernandes da Silva e seu filho mais velho, Francisco Ferreira Gomes Neto. ${ }^{91}$

Seria quase impossível determinar se Gomes Júnior efetivamente nutria animosidade racial contra a população branca de Benguela e conspirava contra a administração colonial. Mas as acusações de 1845 não eram as primeiras dirigidas contra membros do clã Ferreira Gomes por tramar uma rebelião racial. Em 1824, acusações surpreendentemente semelhantes levaram à prisão do patriarca do clã, Francisco Ferreira Gomes, depois que Benguela mergulhou em uma crise política após o Brasil - principal parceiro comercial de Benguela e pátria de vários membros da elite comercial da cidade - tornar-se independente de Portugal. O velho Gomes foi, então, acusado de tramar uma sedição que levaria à anexação de Benguela ao Brasil recém-independente, pondo fim ao controle português sobre a cidade. Mais importante ainda, como aconteceria a seu filho 20 anos depois, também dele disseram que havia planejado aniquilar a população branca da cidade. No entanto, depois de ser mantido na prisão em Luanda, ele foi reabilitado e retornou a Benguela. ${ }^{92}$

Acusações semelhantes surgiram novamente em 1835, quando o velho Gomes já estava morando no Rio de Janeiro. Seus dois filhos foram presos, depois de serem acusados de planejar uma "revolução que talvez, se não tivesse sido suprimida, teria vitimado toda a raça branca" de Benguela. Segundo as autoridades, o velho Gomes teria retornado do Rio a Benguela para se juntar aos seus dois filhos, se a "revolução" tivesse sido bem sucedida. ${ }^{93}$ Para evitar tumultos em Benguela, as autoridades determinaram que "nenhum negro, livre ou escravizado, assim como outros indivíduos, independentemente do seu estatuto legal, podia portar armas durante o dia ou a noite".$^{94}$ Os irmãos Ferreira Gomes foram levados para a cadeia em Luanda e Johannes Ferreira Gomes foi condenado ao exílio em São Tomé..$^{95}$

90 AHA. Ofício do Secretário Geral da Província de Angola, 23/09/1846, cód.3440, fls.183v.-184; AHA. Ofício do Delegado do Procurador da Coroa e Fazenda, 16/04/1847, cód.2788, fl.85; AHA. Requerimento de José Ferreira Gomes, 08/05/1847, cód.2788, fl.94; AHA. Requerimento de José Ferreira Gomes, 03/08/1847, cód.2788, fl.127v. 91 AHA. Passaporte de José Ferreira Gomes, 23/01/1849, cód.523, fl.8v.

92 ALENCASTRO, Luiz Felipe de. Continental drift: the independence of Brazil (1822), Portugal and Africa. In: OLIVIER PÉTRÉ-GRENOUILLEAU (ed.). From slave trade to Empire: Europe and the colonization of Black Africa, 1780s1880s. London/New York: Routledge, 2004, p.98-109.

93 AHU. Carta de Jácomo Felipe Torres, 06/11/1835, segunda seção de Angola, pasta 5.

94 AHA. Bando contra o Uso de Armas de Fogo em Benguela, 20/08/1835, cód.521, fl.4v.-5.

95 AHA. Carta para o Juiz do Crime Interino e Relator da Alçada, 11/08/1835, cód.163, fls.10-10v. Apesar de nunca ter sido levado a São Tomé e Príncipe, Johannes Ferreira Gomes foi mantido na prisão por três anos em Luanda. Ver: AHA. Portaria da Secretaria de Estado da Marinha do Ultramar, 01/02/841, cód.260, fls.9-9v. 
Gomes Júnior, no entanto, foi reabilitado e acabou sendo nomeado juiz de paz, um juiz regular eleito, e comandante de um dos fortes de Benguela. ${ }^{96}$

Em contraste, o incidente de 1845 teve implicações de longo alcance. Apesar de ter sido libertado da prisão, Gomes Júnior enfrentou significativas restrições em suas atividades empresariais. Em 1847, por exemplo, foi autorizado a despachar um de seus barcos para navegar ao longo da costa de Benguela, provavelmente comercializando urzela. ${ }^{97}$ No entanto, suas visitas regulares a Luanda significavam que ele estava, às vezes, ausente de Benguela. ${ }^{98}$ Mais importante ainda, para impedir sua participação no comércio ilegal de escravos, as autoridades forçavam-no a pagar fiança sobre os escravos transportados de Benguela a Luanda. ${ }^{99}$ Isso significava que Gomes Júnior teria que se responsabilizar pelos escravos levados a Luanda para ser reembolsado das fianças. Em 1848, ele pediu permissão para viajar ao Egito com o intuito de encerrar suas operações nesse local. ${ }^{100}$

Não demorou muito para que os problemas financeiros de Gomes Júnior começassem a surgir. Esses foram revelados por uma ação ajuizada em 1858, que guarda notável semelhança com a ação judicial movida contra o velho Gomes no Rio de Janeiro em 1863. Como a ação proposta posteriormente no Rio, esse processo mostrou que disputas financeiras estavam no centro de amargas brigas internas da família. Um homem chamado Domingos Rodrigues Vianna, então casado com a filha de Gomes Júnior, Feliciana Ferreira Gomes Vianna, processou-o devido a dívidas pendentes. Essas resultavam de um dote no valor de quatro contos de réis que a esposa de Gomes Júnior havia pagado a Joannes Manoel Dias de Oliveira, o primeiro marido de Feliciana. Oliveira era um ex-soldado de Benguela, que havia trabalhado na feitoria que Gomes Júnior tinha no Egito. Ele havia morrido em Catumbela, em 1845. ${ }^{101}$

A ação mostrava a extensão das ligações entre a família Gomes Ferreira e o Brasil, uma vez que o dote havia sido enviado ao Rio de Janeiro para ser investido no Banco do Brasil, administrado pelo Estado. Como Gomes Júnior afirmou: "Manoel Joannes, depois de se casar (com Gertrudes Ferreira Gomes), ordenou que tal dinheiro fosse investido no Banco do Brasil". ${ }^{102}$ Na ação, Domingos Rodrigues Vianna afirmava que Gomes Júnior havia viajado ao Rio de Janeiro em 1851 para recuperar o dinheiro, mas

96 AHA. Informação do Delegado, 1839, cód.722; AHA. Ordem do Governador de Benguela, 21/11/1839, cód.522, fls.34-35; AHA. Ofício do Governador de Benguela, 04/10/1848, cód.462, fls.134-134v.

97 AHA. Ofício do Governador de Benguela, 27/09/1847, cód.722, fl.195v.

98 Seus negócios em Benguela eram administrados por um sócio brasileiro chamado Andre Correa Homem de Carvalho. Ver: AHA. Circular aos Moradores de Benguela, 12/09/1846, cód.461.

99 AHA. Requerimento de José Ferreira Gomes, 20/08/1847, cód.2788, fl.135v.

100 Ao autorizar a viagem, as autoridades de Luanda estabeleceram que Gomes Junior deveria depois retornar a Luanda. Ver: AHA. Ofício do Secretário do Governo de Angola, 14/03/1848, cód.326, fl.38; AHA. Ofício do Governador de Angola,14/03/1848, cód.510, fl.70.

101 AHA. Requerimento de José Gomes Ferreira, 20/10/1840, cx.1602.

102 TCB. Autuação de Requerimento de José Ferreira Gomes, 17/08/1857, maço 1, n.40. 
havia se recusado a entregá-lo a ele. ${ }^{103}$ Como resultado da ação judicial, um juiz de Benguela ordenou a apreensão dos escravos de Gomes Júnior e o impediu de receber o pagamento pela venda de dois escravos. ${ }^{104}$ Para evitar o embargo judicial de suas propriedades, Gomes Júnior alegou que elas pertenciam ao velho Gomes, que então vivia no Rio de Janeiro. ${ }^{105} \mathrm{Em}$ duro contraste com a riqueza da família no passado, o processo revelou que Gomes Júnior era proprietário de apenas um escravo, seis fazendas e seis pequenas habitações, conhecidas como cubatas. Como afirmado por Francisco Geraldo Ferreira de Souza Guimarães, ele havia "conhecido o réu (José Gomes Ferreira) em outro momento, quando ele era uma pessoa rica, mas agora ele havia deteriorado" financeiramente. ${ }^{106}$

\section{Conclusão}

Recentemente, David Eltis sugeriu que muito do intenso tráfico de escravos entre Angola e o Brasil derivava de forças ambientais, em particular do regime de ventos e correntes no oceano Atlântico, que aumentaram as trocas marítimas entre as duas regiões. ${ }^{107}$ Este artigo, ao contrário, argumentou que laços transatlânticos sociais, econômicos e culturais, como os construídos pela família Gomes Ferreira e por outros comerciantes de Benguela, estavam no núcleo das complexas relações entre as duas regiões. Apesar de tais laços terem permitido que os traficantes de escravos contornassem as primeiras medidas anti-tráfico, as políticas portuguesas que procuravam restringir os embarques de escravos acabaram por afetar os grupos locais envolvidos no comércio de escravos. Essas políticas eram parte de projetos mais amplos para mudar a economia angolana, distanciando-a do tráfico negreiro e reforçando os laços econômicos entre Angola e Portugal. Da mesma forma, elas foram concebidas para eliminar ameaças britânicas ao controle português sobre o litoral de Angola. A luta para acabar com o tráfico de escravos contrapunha os administradores coloniais portugueses aos grupos brancos, negros e mestiços que controlavam o tráfico de escravos na costa angolana, produzindo instabilidade política e tensão racial em Luanda e em Benguela.

103 TCB. Libelo de Domingos José Vianna, 28/06/1855, n.2251

104 TCB. Ofício do Delegado do Procurador Régio da Fazenda, 28/08/1855, Autos Cíveis de Embargo ou Arresto, maço 7, n.309; TCB, Autuação de Requerimento de José Ferreira Gomes, 17/08/1857, maço 1, n.40.

105 TCB. Auto de Sentença Cível, 1858, maço 2, n.85.

106 TCB. Autos Cíveis de Embargo ou Arresto, 1858, maço 1, n.47.

107 ELTIS, David. Was the abolition of the U.S. and British slave trade significant in the broader Atlantic context? William and Mary Quarterly, v.LXVI, n.4, p.718, 2009. 